\title{
A inclusão social de usuários dos Centros de Atenção Psicossocial álcool e outras drogas de um município paulista*
}

\author{
Silvana Proença Marchetti \\ Di https://orcid.org/0000-0001-5451-1226 \\ Toyoko Saeki ${ }^{1}$ \\ (D) https://orcid.org/
}

Objetivo: investigar a inclusão social de usuários em atendimento em dois Centros de Atenção Psicossocial Álcool e Outras Drogas, na cidade de Campinas - SP, sob a perspectiva dos profissionais que neles atuam. Método: neste estudo qualitativo, os dados foram analisados segundo o método de análise de conteúdo, na especificidade análise temática. Resultados: o estudo permitiu desdobramentos em três categorias: 1-) a visão do profissional sobre inclusão social dos usuários problemáticos de drogas; 2-) o cuidado à inclusão social; e 3-) os limites e potencialidades para inclusão social desses usuários. Conclusão: o posicionamento político-ideológico dos profissionais e suas considerações sobre sofrimento ético-político têm influência sobre os modelos de atenção aos usuários.

Descritores: Saúde Mental; Serviços de Saúde Mental; Inclusão Social; Usuários de Drogas.

\section{Como citar este artigo}

Marchetti SP, Saeki T. Social inclusion of drug users at a Service of Psychosocial Attention and Care to alcohol and drug addiction in a city in the State of São Paulo. SMAD, Rev Eletrônica Saúde Mental Álcool Drog. 2019;15(4):1-8. doi: https://dx.doi.org/10.11606/issn.1806-6976.smad.2019.151283 


\title{
Social inclusion of drug users at a Service of Psychosocial Attention and Care to alcohol and drug addiction in a city in the State of São Paulo
}

\begin{abstract}
Objective: was to investigate the social inclusion of users in care on two Psychosocial Care Centers Alcohol and Drugs, of the city Campinas-SP, from the perspective of the professionals who work in them. Method: in this qualitative study, the data were analyzed according to the content analysis method, in the specificity thematic analysis. Results: the analysis allowed for unfolding in three thematic categories: the professional's view on social inclusion of problem drug users; care for social inclusion; and the limits and potentialities for social inclusion of these users. Conclusion: it was concluded that there is influence of assistance models for users in politicalideological positioning of professionals and their consideration to the ethico-political suffering.
\end{abstract}

Descriptors: Mental Health; Mental Health Services; Social Inclusion; Drug Users.

\section{La inclusión social de los usuários de los Centros de Atención Psicosocial alcohol y otras drogas de un municipio paulista}

Objectivo: investigar la inclusión social de usuarios en atención en dos Centros de Atención Psicosocial Alcohol y Drogas, en la ciudad de Campinas - SP, bajo la perspectiva de los profesionales que en ellos actúan. Metodo: en este estudio cualitativo, los datos fueron analizados según el método de análisis de contenido, en la especificidad de análisis temática. Resultados: el análisis permitió desdoblamientos en tres categorías temáticas: la visión del profesional sobre inclusión social de los usuarios problemáticos de drogas; el cuidado a la inclusión social; y los límites y potencialidades para la inclusión social de esos usuarios. Conclusión: es que hay influencia de los modelos de asistencia para usuarios en el posicionamiento político-ideológico de los profesionales y su consideración al sufrimiento ético-político.

Descriptores: Salud Mental; Servicios de Salud Mental; Inclusión Social; Usuarios de Drogas. 


\section{Introdução}

Há diferentes discussões dentro do campo da saúde sobre o cuidado prestado à população usuária de drogas. Em especial no que diz respeito aos modelos de atenção à saúde para usuários problemáticos de álcool e outras drogas no Brasil, os cuidados são embasados em dois principais paradigmas: o proibicionista e a abordagem de redução de danos(1). Está entre os objetivos do primeiro a redução da oferta e da demanda de drogas por meio de intervenções de repressão e criminalização da produção, tráfico, porte e consumo de drogas ilícitas. Já o objetivo que permeia a segunda abordagem é promover ações orientadas para minimização dos danos à saúde, sociais e econômicos relacionados ao consumo de drogas, sem prioritariamente coibi-las.

Reflete-se aqui sobre as práticas em saúde mental aos usuários problemáticos de álcool e outras drogas no que diz respeito à inclusão social dessas pessoas, pois compreende-se que tal inclusão é um importante alicerce de cuidado. Assume-se o pressuposto de que a perspectiva dos profissionais sobre tal integração expressa em quais modelos de atenção para usuários de álcool e outras drogas suas práticas estão fundamentadas e, consequentemente, sua perspectiva político-ideológica sobre o fenômeno das drogas.

Compreende-se que a saúde é um direito, pois a Constituição Brasileira de 1988 menciona, em seu artigo 196, o direito à saúde para todos; sendo dever do Estado garanti-lo e responsabilizar-se pela criação de políticas públicas e suas aplicações. O mesmo artigo estabelece que o direito à saúde deve ser garantido mediante políticas sociais e econômicas com o objetivo de reduzir riscos de doenças e outros agravos e que o acesso deve ser universal e igualitário para ações e serviços que favoreçam promoção, proteção e recuperação(2).

O acesso dos usuários problemáticos de drogas à saúde necessita de uma importante ponderação: apesar das críticas no discurso público quanto à própria operacionalização insuficiente do sistema de saúde, há também falhas na execução desses princípios, em especial referente a esta população, pois há um estigma social imposto sobre eles e uma difícil compreensão sobre o fenômeno das drogas.

No que se refere a essa ponderação existe significativa estigmatização sobre as drogas e seus usuários(3). Para o autor, a ausência de um debate público e a repetição de uma ideia falsa, preconceituosa e autoritária reduzem os reais problemas estruturais da sociedade. Manter essa situação, por sua vez, seria útil à sociedade, visto que auxilia na manutenção do status quo, ainda que aumente a marginalização dos usuários. Assim, impõe-se, para o autor, um distanciamento da construção de um modelo de atenção à saúde do usuário de drogas que seja isento de ações que os marginalizem ou excluam socialmente.

Desta forma, este artigo apresenta uma pesquisa que teve como objetivo investigar a inclusão social de usuários em atendimento nos Centros de Atenção Psicossocial Álcool e Outras Drogas (CAPS ad) localizados no município de Campinas - SP, sob a perspectiva dos profissionais. Ainda, para isso, houve a necessidade de traçar três objetivos específicos: 1) descrever as ações realizadas pelos profissionais dos CAPS ad; 2) identificar as ações que favorecem a inclusão social dos usuários desses serviços; e 3) identificar os limites e potencialidades institucionais para a inclusão social de tais usuários.

\section{Método}

Trata-se de uma pesquisa descritiva exploratória com abordagem qualitativa dos dados, em virtude da natureza do objeto de estudo e objetivo proposto. Para investigar a perspectiva dos profissionais sobre inclusão social de usuários problemáticos de álcool e outras drogas, optou-se por um método qualitativo da pesquisa social em saúde, pois o objeto do estudo é histórico e, portanto, mutável no espaço e tempo, o que pode sofrer transformações de acordo com seu contexto(4).

Para a realização deste recorde empírico, cuja constituição teórica será descrita neste artigo, estabeleceu-se, segundo orientação de Minayo(4), a combinação de entrevistas semiestruturadas, observação participante e documentos bibliográficos que confirmaram os pressupostos, de forma a conferir sequência ao estudo.

Considera-se que a inclusão social de usuários problemáticos de álcool e outras drogas pode ser vista por diversas perspectivas, sendo elas: a dos usuários dos serviços e seus profissionais; a das instituições públicas ou privadas; e a da sociedade, de forma geral. Porém, são os profissionais dos serviços CAPS ad que estão ligados diretamente ao cuidado específico dessa população, aos processos de trabalhos adaptados a essa lógica e situados em uma posição estratégica para possíveis análises sobre a complexidade que o fenômeno das drogas compreende. Assim, tais profissionais estão diante da realidade dos usuários problemáticos de álcool e outras drogas e seus fenômenos. Também estão instrumentalizados para um cuidado que pode compreender diferentes perspectivas políticoideológicas no que diz respeito à especificidade desse tipo de atendimento, além de analisar o que de fato está sendo ofertado a essa população, em uma cidade que é considerada referência no cuidado em saúde mental.

A coleta de dados foi realizada de setembro a novembro de 2014 em dois CAPS ad da cidade de 
Campinas com a utilização de um diário de campo para registro das experiências vivenciadas.

Foram entrevistados 17 profissionais de níveis superior e médio que atuavam na atenção direta aos usuários do serviço. Para a entrevista semiestruturada foi elaborado um roteiro com três questões norteadoras: 1) quais são suas atividades neste serviço e como são realizadas?; 2) descreva, entre suas ações, quais favorecem a inclusão social do usuário deste serviço; e 3) quais são os limites e as potencialidades do CAPS ad para a inclusão social do usuário desse serviço? Vale lembrar que todos os entrevistados assinaram o Termo de Consentimento Livre e Esclarecido e, em 27 de maio de 2014, a pesquisa foi autorizada pelo Comitê de Ética em Pesquisa da Escola de Enfermagem de Ribeirão Preto/Universidade de São Paulo (EERP/USP).

Com base nas informações coletadas, os dados foram organizados e explorados segundo o método de análise de conteúdo na especificidade análise temática.

\section{Resultados}

Os profissionais dos CAPS ad estudados descreveram as atividades por eles desenvolvidas de formas bastante semelhantes, especificando-as em ações internas e externas, sendo as primeiras aquelas realizadas dentro do serviço e, as segundas, no território onde os serviços estão inseridos.

Dessa forma, citaram como atividades externas: visitas domiciliares, atividades de redução de danos em campo, matriciamento, busca ativa, acompanhamento terapêutico e reuniões (como aquela entre representantes das redes de atenção básica e de saúde mental, reuniões dos distritos de saúde, do conselho gestor e conselho municipal de saúde, e algumas oficinas - por exemplo, de esporte).

Já entre as atividades realizadas dentro do serviço citadas pelos participantes, estão atividades dos núcleos, ou seja, atividades específicas de determinada categoria profissional. No núcleo da psicologia, seriam os atendimentos psicoterapêuticos individuais ou grupais; no núcleo da terapia ocupacional, os ateliês; no núcleo da enfermagem, aquelas relacionadas aos cuidados de enfermagem; no núcleo da redução de danos, as voltadas para ações de redução de danos na ambiência; no núcleo médico, atividades relacionadas aos atendimentos individuais; no núcleo da farmácia, pertinentes ao armazenamento e dispensação de medicamentos e materiais; e no núcleo da assistência social, aquelas de atendimento individual da assistência social.

Além dessas, outras foram citadas, comuns a todos os núcleos: atividades de acolhimento, passagem de plantão, assembleia, oficinas e atividades de profissional ou técnico de referência, como negociações e cuidados terapêuticos dispensados ao usuário.
A análise dos dados teve como base a construção de três temas. Estes foram criados a partir da importância e frequência com que alguns dados emergiram, bem como da necessidade que o estudo abarca, segundo a metodologia escolhida. O primeiro tema foi "As visões dos profissionais sobre a inclusão social dos usuários problemáticos de álcool e outras drogas"; o segundo, "O cuidado à inclusão social"; e, o terceiro, "Os limites e potencialidades para inclusão social dos usuários problemáticos de álcool e outras drogas".

As visões dos profissionais sobre a inclusão social dos usuários problemáticos de álcool e outras drogas foram diversas. A inclusão social se daria, por exemplo, pela inserção no mercado de trabalho ou em atividades de educação; pela circulação na rede de saúde e em outros equipamentos comunitários; pelo exercício da autonomia; pelo trato do profissional com o usuário; pela não associação do usuário problemático de álcool e outras drogas a um criminoso; e, por último, pela melhora da autoestima e aparência social do usuário.

Sobre o cuidado à inclusão, os entrevistados - de forma geral - afirmaram que realizam ações de inclusão social para essa população. As ações colocaram-se de três diferentes formas: a primeira seria de um cuidado amplo, não restrito à clínica ou a ações no território, e que ainda deveria estar contida na lógica do modelo de redução de danos. A segunda seria o cuidado com a inclusão, que é possível, de acordo com a análise, se houvessem ações mais médico-centradas e não norteadas pela redução de danos, exemplificadas a seguir: acho que se tivesse um médico psiquiatra aqui e um clínico, pelo menos, a coisa ia ser diferente! A gente conseguiria muito mais sucesso na reinserção do indivíduo na sociedade, com um tratamento que ele conseguisse levar mais a sério porque ninguém leva a sério o tratamento aqui do paciente. (Entrevistado A8); na minha opinião, a gente trabalha aqui mais com redução de danos, a gente não trabalha com a recuperação total do indivíduo, acho que isso. (Entrevistado A8).

A terceira seria a inclusão social não como foco do seu trabalho, já que ela seria uma situação ideal e utópica: eu posso dizer que é sucesso terapêutico que não necessariamente é reinserção social como a gente imagina e idealiza. (Entrevistado A9); o usuário de cocaína, que tem esquizofrenia, qual o prognóstico que esse cara tem, sabe? Eu vou esperar que esse cara volte ao mercado de trabalho formal? (Entrevistado A9).

No terceiro tema, dentre os limites e potencialidades para a inclusão social dos usuários problemáticos de álcool e outras drogas, foram apontados pelos participantes não apenas seus limites e suas potencialidades para ações de inclusão social, mas, também, os da instituição CAPS ad, bem como aqueles que a extrapolam. 
Os profissionais relataram como principal fator limitante para a inclusão a ausência de capacitação e preparo dos profissionais para as ações de inclusão social, além da falta de apropriação das discussões políticoideológicas relacionadas ao atendimento ao usuário. A esse respeito, consideraram como potencialidade o próprio conhecimento específico para o cuidado dessa população e a presença de um posicionamento políticoideológico quanto ao uso problemático de drogas e, consequentemente, o modelo de atenção que se apropria.

Quando questionados sobre os limites dos CAPS ad para a inclusão social dos usuários, os entrevistados apontaram a falta de recursos humanos e de transporte institucional. Além disso, mencionaram as dificuldades políticas entre a Prefeitura Municipal de Campinas e o Serviço de Saúde Dr. Cândido Ferreira, parceria esta de cogestão da assistência à saúde mental do município.

A gente tá em um momento complicado com a política... que o convênio Cândido Ferreira, que é quem sustenta a saúde mental em Campinas, então... tá sempre... prefeitura não tá querendo muito essa parceria com o Cândido, mas também não tem coragem de dizer... e, com isso, o sucateamento dos serviços tá sendo bem importante, tá limitando ainda mais. (Entrevistado A1).

No que se refere aos fatores potencializadores institucionais, foram destacados: a existência da retaguarda noturna nos CAPS ad, chamada de leitonoite, e o núcleo de oficinas de trabalho, que seriam atividades laborais com baixa remuneração, porém com competitividade de mercado, gerida pelo próprio Serviço de Saúde Dr. Cândido Ferreira.

Além disso, foram referidos outros fatores limitantes, os quais extrapolam os serviços, como a perspectiva moralista da sociedade em relação ao usuário problemático e o desalinhamento das políticas em álcool e outras drogas. Ainda, sobre a potencialidade que extrapola a instituição, ressalta-se que o CAPS ad recebe novos usuários sem a necessidade de encaminhamento ou qualquer outro tipo de burocracia, conforme a portaria que regulamenta tais serviços.

\section{Discussão}

Durante a pesquisa, fica exposta a amplitude que o estudo abarca, o que possibilita uma discussão em diferentes planos, do micro ao macro, sobre fatores que influenciam a inclusão social dos usuários problemáticos de álcool e outras drogas atendidos em serviços especializados, como os CAPS ad, bem como as políticas públicas que os regulamentam.

Dentro da análise dos conceitos utilizados, vale ressaltar a discussão dos conceitos de inclusão e exclusão social. O conceito de exclusão pode ser considerado "conceito mala ou bonde", pois pode ser atribuído a qualquer fenômeno social, sem que se saiba ao certo quais os significados contidos ${ }^{(5)}$. A autora também assinala que muitos estudiosos preferem substituí-lo por uma expressão mais precisa, embora considere que o termo seja frequentemente compreendido como sinônimo de pobreza, o que acaba minimizando a questão central que nele reside: a injustiça social(5).

Sob essa perspectiva, compreende-se injustiça social como parte da constituição da organização social capitalista, visto que, para que haja "incluídos", é necessária a existência de "excluídos". Assim, a sociedade exclui para incluir, portanto, pode-se dizer que a inclusão passa a ser meramente ilusória sob o ponto de vista econômico, pois todos estão inclusos, mesmo que com insuficiências e privações ${ }^{(5)}$.

Propõe-se, portanto, uma perspectiva que é a da ética e da subjetividade na análise sociológica da desigualdade, o que favorece um olhar amplo sobre "inclusão", neste caso não circunscrito à necessidade de ações do Estado diante das injustiças sociais e do sistema de empregabilidade, mas sim no sentido de haver descompromisso com o sofrimento político do outro(5). $^{(5)}$

Apesar da utilização da expressão "inclusão social", referimo-nos à concepção empregada por essa mesma autora, que utiliza o termo "dialética da inclusão/exclusão". Dessa forma, desatrela a ideia de inclusão como normatização ou padronização social e aproxima-se do sentir-se incluído, que se "manifesta no cotidiano como identidade, sociabilidade, afetividade, consciência e inconsciência"(5).

Portanto, os profissionais indicam uma perspectiva ampla, da mercadológica a dos afetos no cotidiano, sobre o que seria a inclusão social da população que eles atendem. Entretanto, essas diferentes concepções apontadas pelos entrevistados, vistas de forma isolada, descontextualizada, ainda podem ser consideradas alternativas perversas de inclusão(5).

Nesse sentido, a inclusão perversa descrita pela mesma autora seria uma forma mascarada de inclusão que denota a apropriação de materiais ou símbolos que apenas ilusoriamente os fazem sentir parte do todo. Tratar-se-ia de uma tentativa frustrada de inclusão, pois se exclui para incluir, mantendo esses usuários dependentes do Estado (ou serviços), em especial no que diz respeito à liberdade; situação que gera a falsa ideia de satisfação segundo a lógica mercadológica(6).

Do ponto de vista das falas dos profissionais, analisa-se que algumas ações de inclusão, como inserção no mercado de trabalho, podem ser consideradas mercadológicas quando se pensa que a inclusão social só é possível quando esta inserção ocorre. A inclusão social se faz presente na ética da subjetividade e não se circunscreve às ações do Estado para com as injustiças do sistema de empregabilidade, mas sim quando há cuidado com seu sofrimento ético-político(5). 
Ainda, quando se considera as perspectivas de inclusão social por meio do desenvolvimento da autonomia, a circulação desses usuários pelas redes de atenção de saúde (como a Rede de Atenção Psicossocial e a Rede de Atenção à Saúde) é uma ação de inclusão que de fato possibilita a consideração pelo seu sofrimento ético-político e, consequentemente, a possibilidade de sua inclusão social.

O trato de forma afetiva no cotidiano do profissional com o usuário está em considerar seu sofrimento éticopolítico e, portanto, também não levar em conta uma percepção moralista do usuário, a exemplo de pensá-lo como um criminoso. Desta forma, permite-se a verificação de que a perspectiva dos profissionais sobre o consumo problemático de drogas está inserida no modelo de redução de danos, pois o considera não sob a ótica moral ou criminal, mas como um problema de saúde pública(1).

As situações de vulnerabilidade a que estão expostos os usuários para que possam utilizar drogas podem ser minimizadas no momento em que o Estado, por meio de políticas públicas, possibilitar um consumo seguro e não estigmatizado, que leva o usuário a aproximar-se de uma relação de cuidado em saúde.

Embora boa parte dos profissionais posicionem-se a favor do modelo de atenção de redução de danos, há ainda um posicionamento de uma parcela deles que é favorável ao modelo proibicionista de atenção. Esse olhar é bastante emblemático para compreender como alguns profissionais se posicionam diante do cuidado à inclusão social. Nesse caso, pode-se notar grande frustração por parte deles de certo modo compreensível -, pois o objetivo imposto é o da abstinência, não incluindo outras facetas igualmente importantes relacionadas ao consumo de drogas.

O posicionamento dos profissionais acerca da inclusão social não é o foco do seu trabalho; consideram-na inclusive uma ação utópica. Sendo assim, mesmo que de maneira sutil, fica expressa a não identificação de ações que oportunizam a inclusão social.

Diante do exposto, compreende-se que a inclusão social ainda não é um tema bem definido pelas equipes e, portanto, requer muitas discussões no que diz respeito ao potencial de uma ação de afeto, aparentemente simples, na gênese de um cuidado ao sofrimento éticopolítico e, consequentemente, da promoção de dignidade e inclusão social(5).

Já os limites e potencialidades para a inclusão social dos usuários, os participantes apontaram seu preparo para o cuidado com os usuários de drogas como limites e potencialidades a ele relacionados. Assim, podem oferecer seu conhecimento e sua qualificação em prol da inclusão social. Ainda, o principal fator limitador seria a ausência desta capacitação.

A apropriação do profissional em relação às políticas públicas em saúde possibilita a inclusão social porque, mesmo por meio de ações indiretas de cuidado como encaminhamento a serviços da atenção básica, matriciamentos, entre outras ações no território -, os profissionais necessitam de conhecimento prévio de tais políticas. Além disso, também é necessário que tenham clareza sobre políticas de saúde mental e seus fluxos, pois, dessa forma, executam ações de saúde voltadas ao território e não somente ambulatoriais ou hospitalares. Portanto, a apropriação teórica e prática das políticas em saúde leva esses profissionais a realizarem ações de inclusão social em prol dos usuários.

Ainda como fator limitante para ações de inclusão social, tem-se a ausência ou escassez de suportes institucionais e recursos materiais (a exemplo da falta de transporte institucional), o que desestimula a realização de atividades no território, como visitas domiciliares, matriciamentos, entre outras. No entanto, essas ações deveriam ser prioritárias, visto que são preconizadas pelas políticas em saúde para o cuidado integral, no território e em rede(7).

As fragilidades institucionais interferem de forma direta na Atenção Psicossocial aos usuários problemáticos de drogas e, consequentemente, em ações de inclusão social. A baixa qualificação da assistência prestada pelo Sistema Único de Saúde (SUS) evidencia-se não apenas pelos problemas financeiros, materiais e tecnológicos, mas quando a eles somam-se apatia burocrática, corporativismo e/ou omissão profissional, falta de ética e respeito aos profissionais e usuários ${ }^{(8)}$. Essas situações, por sua vez, geram pouca produtividade, baixa cobertura dos serviços e, em especial, sofrimentos. Assim, a gestão de qualidade de serviços públicos alicerçados nas políticas do SUS representa o principal desafio à reforma sanitária brasileira ${ }^{(8)}$ e, consequentemente, à reforma psiquiátrica, com repercussões na assistência aos usuários.

Por outro lado, os fatores relacionados ao CAPS ad que potencializam a inclusão social seriam as estruturas da rede de atenção psicossocial de Campinas, como o dispositivo de leito-noite e o Núcleo de Oficinas de Trabalho (NOT) utilizados no cuidado ao usuário no território; porém, a utilização desses dispositivos sem que haja a sensibilidade do profissional ao sofrimento ético-político dos usuários deixa de ser suficiente para sua inclusão social.

De forma geral, embora o SUS tenha ampliado o acesso da população brasileira aos cuidados de saúde ao incluir usuários problemáticos de álcool e outras drogas, permanecem problemas na equidade desse direito. Há, nesse sentido, uma luta para a garantia da cobertura universal e equitativa, considerando que a participação do setor privado cresce e emergem contradições, sobretudo no que diz respeito a ideologias e objetivos a busca do acesso universal contrapondo-se à segmentação do mercado( ${ }^{(9)}$.

Além da participação do setor privado na elaboração das políticas e sua interferência negativa nas premissas básicas do SUS no que diz respeito às políticas de saúde para usuários problemáticos de álcool e outras 
drogas, existe, ainda, a complexidade que o fenômeno das drogas acrescenta a essa discussão, pois, sob uma perspectiva histórica, social e econômica, diferentes visões do fenômeno puderam ser traçadas, fato que interfere diretamente na consolidação de modelos de atenção à saúde.

A discussão sobre a questão do uso de drogas é, de fato, bastante ampla. O consumo dessas substâncias é milenar e esteve presente em grande parte das culturas, com diferentes finalidades: médicas, religiosas e sociais ${ }^{(10)}$. Importante esclarecer que o autor não se refere apenas ao álcool, considerado indispensável em certos ritos de cura, devoção, consolo e prazer. A diferenciação que se faz na história da humanidade em relação ao consumo reside nas distintas formas de uso e controle social.

No que se refere ao controle social, ainda de acordo com o autor, a regulamentação formal das drogas teve início no século $X X$, época em que algumas substâncias eram aceitas e outras não, sendo o critério para tal distinção baseado em imposições culturais e econômicas. Do mesmo modo, na contemporaneidade, o uso de drogas distingue-se pela forma de consumo e regulamentação, o que permite inferir, no que diz respeito à atenção dispensada aos usuários problemáticos de álcool e outras drogas, que diferentes modelos de atenção à saúde são criados para essa população.

Dessa forma, tem-se que o consumo problemático de álcool e drogas está intimamente relacionado com a forma como nos organizamos socialmente. Atualmente, nossa organização baseia-se no modo de produção capitalista, que está sincronizado com os movimentos individuais e compulsivos de satisfazer os desejos o mais rápido possível e não sentir dor, seja ela qual for. A droga, nesse contexto, pode ter o efeito anestésico(11) de uma vida líquida(12).

Sendo assim, vincular tantas esferas de saberes e considerá-las fenômenos intrínsecos uns aos outros constitui importante passo para a construção de novos conhecimentos em saúde mental e saúde pública. Do mesmo modo, para a produção de ações que visem à integralidade do sujeito de sofrimento ou "usuário do serviço", são necessários novos saberes atrelados anteriormente a uma perspectiva de cidadão de direitos, nesse caso não apenas o cidadão com poder de consumo, mas produtor de conhecimento e História.

Diante do exposto e com base nas leituras realizadas a respeito das políticas de saúde sobre drogas, observam-se algumas contradições acerca de uma ideologia da atenção psicossocial aos usuários de drogas. No Brasil, apesar de vigorarem políticas de saúde voltadas à redução de danos, ainda há um posicionamento proibicionista que possibilita a abertura de diferentes formas de atuação no campo da saúde, em especial aquelas realizadas para o cuidado dos usuários problemáticos de drogas.
A esse respeito, o Ministério da Saúde reconhece haver uma lacuna no que tange às políticas públicas de saúde sobre drogas, atribuindo para si a responsabilidade pela instituição da justiça, segurança pública, pedagogia, benemerência e associações religiosas, o que propiciou a disseminação de uma prática predominantemente medicamentosa, disciplinar e de cunho religioso ${ }^{(13)}$. Prevalece, nesse contexto, o modelo de tratamento exclusivamente voltado à abstinência, o que contribui para reforçar o isolamento social e o estigma associado ao uso de drogas.

Vale ainda lembrar que, mesmo com a descriminalização das drogas, o sistema permanecerá perverso com o usuário, pois, ainda que não seja mais visto como criminoso ao consumi-las, precisará se expor para comprá-las em um sistema ilegal, ou seja, no tráfico de drogas. Dessa forma, sugere-se que com a legalização das drogas o usuário não será mais visto como um criminoso perante a lei e, assim, poderá fazer uso de forma a não corroborar com um sistema gerador de vulnerabilidades e sofrimentos, como é o do tráfico.

Sob tal perspectiva, a violência se encontra muito mais atrelada ao tráfico e à repressão policial do que ao uso das drogas ${ }^{(14)}$. Ainda segundo ele, a violência (a inclusão de usuários e trabalhadores no tráfico) possui relação sobretudo com a exclusão social e a tradição de masculinidade.

Portanto, sob a perspectiva dos profissionais, as ações de inclusão social dependem de fatores sociais relacionados ao contexto sócio-histórico contemporâneo; acresce-se que a estrutura legislativa brasileira para usuários ainda é bastante conservadora e promotora de exclusões, já que o tráfico de drogas parece ser o grande responsável pelas vulnerabilidades.

\section{Conclusão}

Os resultados evidenciam que as práticas em saúde mental voltadas à inclusão social de usuários problemáticos de álcool e drogas nos CAPS ad estudados ainda são superficiais no que diz respeito à complexidade da inclusão social desses usuários.

Segundo os participantes, ocorrem ações de inclusão social dos usuários, mas, para que sejam realmente efetivas, dependem da forma como o profissional se posiciona política e ideologicamente em relação ao uso problemático de drogas e à consonância dos fatores externos aos serviços de modo que os favoreçam, como as políticas públicas nacionais em saúde e acordos municipais entre instituição e prefeitura.

De fato, a perspectiva dos profissionais sobre inclusão social revela que a maioria deles se norteia pelo modelo de atenção de redução de danos; porém, persistem posicionamentos pouco esclarecidos quanto ao modelo de atenção qualificado a essa população, bem como se notam posturas mais condizentes com o modelo proibicionista. 
É importante ressaltar que esta pesquisa apresenta uma estrutura de análise qualitativa e, portanto, deve ser considerado para outras análises, a partir deste estudo, o contexto histórico e cultural da região estudada. Ademais, para averiguar a questão da inclusão social, esta pesquisa partiu da perspectiva dos profissionais dos serviços CAPS ad, o que seria mais aprofundado a partir da perspectiva de outros profissionais da Rede de Atenção Psicossocial e da Rede de Atenção a Saúde, bem como dos próprios usuários e da sociedade.

Entende-se, portanto, que ainda são necessários debates públicos e pesquisas sociais e de saúde quanto ao fenômeno das drogas, especialmente no que se refere ao cuidado em saúde a essa população, pois há a importância de considerar o modelo de redução de danos nem como uma estratégia de cuidado nem como um posicionamento político-ideológico exclusivamente, mas sim um modelo de cuidado clínico e institucional nacional.

Ainda, as discussões permanentes nas equipes de serviços substitutivos, como CAPS ad, e em outros dispositivos da rede de saúde para atenção aos usuários problemáticos de álcool e outras drogas necessitam considerar o sofrimento ético-político de tais pessoas, pois são formas de possibilitar o desenvolvimento de práticas em saúde mental que promovam inclusão social em toda sua complexidade.

\section{Referências}

1. Alves VS. Modelos de atenção à saúde de usuários de álcool e outras drogas: discursos políticos, saberes e práticas. Cad Saúde Pública. 2009 Nov; 25(11). Disponível em: http://www.scielo.br/scielo.php?pid=S0102311X2009001100002\&script=sci_abstract\&tlng=pt.

2. Constituição, 1988 (BR). Constituição da República Federativa do Brasil. Brasília, DF.Senado Federal.Seção II da Saúde. Artigo 196. 1988. Disponível em https://www2. senado.leg.br/bdsf/bitstream/handle/id/518231/CF88_ Livro_EC91_2016.pdf.

3. Macrae E. A Abordagem Etnográfica do Uso de Drogas. In: Mesquita F, Bastos F, organizadores. Drogas e Aids Estratégias de Redução de Danos. São Paulo: HUCITEC; 1994. p. 99-114. Disponível em http://www.giesp.ffch. ufba.br/Textos\%20Edward\%20Digitalizados/13.pdf.

4. Minayo MCS. O desafio do conhecimento: pesquisa qualitativa em saúde. 11ed. São Paulo: Hucitec; 2008.

5. Sawaia B. As artimanhas da exclusão - Análise psicossocial e ética da desigualdade social. In: Sawaia B, organizador. Petrópolis: Editora Vozes, 1999.
6. Bertini FMA. Sofrimento ético-político: uma análise do estado da arte. Rev Psicol Soc. 2014; (26) 60-9. Disponível em: http://www.scielo.br/pdf/psoc/v26nspe2/ a07v26nspe2.pdf.

7. Ministério da Saúde (BR). Portaria no 3.088, de 23 de dezembro de 2011. Diário Oficial da União, no 96, de 21.05.2013, Seção 1, p. 37/38. Brasília - DF. Disponível em http://bvsms.saude.gov.br/bvs/saudelegis/gm/2011/ prt3088_23_12_2011_rep.html.

8. Sá MC, Azevedo CS. Subjetividade e gestão: explorando as articulações psicossociais no trabalho gerencial e no trabalho em saúde. Rev Cienc Saúde Coletiva. 2010; 15(5):2345-54. Disponível em http://www.scielo.br/ scielo.php?pid $=$ S141381232010000500010\&script $=$ sci_abstract\&tlng=pt.

9. Paim J, Travassos C, Almeida C, Bahia L, Macinko J. O sistema de saúde brasileiro: história, avanços e desafios. Lancet. 2012. Disponível em: http://actbr.org.br/uploads/ arquivo/925_brazil1.pdf.

10. Carneiro H. As necessidades humanas e o proibicionismo das drogas no século XX. Rev IES (São Paulo) 2002;(6)115-28. Disponível em: http://www.neip. info/downloads/t_hen2.pdf.

11. Xavier D; Niel M. Drogas e Redução de Danos: uma cartilha para profissionais de saúde. In: Marcelo Niel, Silveira DX, organizadores. São Paulo. Drogas e Redução de danos: uma cartilha para profissionais de saúde. 2008. Disponível em:https://www.prefeitura.sp.gov.br/ cidade/secretarias/upload/direitos_humanos/Cartilha\%20 para\%20profissionais\%20da\%20saude.pdf.

12. Bauman Z. Vida líquida. Rio de Janeiro: Jorge Zahar; 2007. 110 p.

13. Ministério da Saúde (BR). Secretaria de Atenção à Saúde/DAPE. Saúde mental no SUS: acesso ao tratamento e mudança do modelo de atenção. Relatório de gestão 2003-2006. Brasília; 2007. Disponível em: http://bvsms. saude.gov.br/bvs/publicacoes/relatorio_gestao_saude_ mental_2003-2006.pdf.

14. Adorno RCF. Uso de álcool e drogas e contextos sociais da violência. SAMD Rev Eletrônica Saúde Mental Álcool e Drogas. 2008;(4)1. Disponível em: http:// pepsic.bvsalud.org/scielo.php?script=sci_arttext\&pi $\mathrm{d}=$ S1806-69762008000100002. 